\title{
Competitiveness Management in Motor Transport Enterprises
}

\author{
Volodymyr Shynkarenko, Oksana Kryvoruchko and Iryna Fedotova ${ }^{1}$, \\ Kharkiv National Automobile and Highway University, Department of Management and \\ Administration, 61002 Ya. Mudrogo str. 25, Kharkiv, Ukraine
}

\begin{abstract}
The theoretical rationale for the model of developing a strategy for competitiveness managing based on a combination of the positioning and provisions of the resource approach theory is given. The management strategy is being developed at the upper (strategic) and medium (tactical) levels. At the upper level, there is a positioning of the enterprise environmental requirements potential. At the level of individual strategic business units (SBU) - analysis by the method of M. Porter, the possibilities are determined on the basis of provisions of the resource approach. Formation of a common competitiveness management strategy is a compromise of a common strategy project with SBU enterprise strategies. The composition of the competitiveness management system of enterprise is validated: the main subsystems, their functions and interrelations between them are defined. Particular attention is paid to the management subsystem, which consists of three subsystems: structural and functional, self-development and informational and behavioral. The main functions of the decision, transforming and information controlling blocks at all management levels are defined. A model of structure of the enterprise competitiveness management system is proposed. Under strategic management, the development of functional strategies is proposed to be transferred to the upper and middle management levels. Using the matrix management structure of the functional units of the enterprise is suggested.
\end{abstract}

\section{Introduction}

Competitiveness management of the enterprise is the current interest problem of the economic objects development. Dissertations of many Ukrainian and foreign researches are devoted to the study of this problem. On many issues of this problem, there is no consensus among scientists. These contradictions begin with the definition of the concept "competitiveness management of the enterprise", with its separation into an independent type of management, with the definition of its content. Changes in economic science over the past five years, in terms of the theory and methodology of developing an enterprise strategy, have put on the agenda the issue of changing of an enterprise and its competitiveness management methods.

The development of the strategic management theory led to the need of clarifying the functions distribution between levels of government. The noted circumstances require bringing the methodology of competitiveness management to the accordance with the today's circumstances. Therefore, the problem of improving the enterprise competitiveness management is relevant and is the purpose of this study.

\footnotetext{
${ }^{1}$ Corresponding author: irina7vf@gmail.com
} 
The object of the study is motor transport enterprises, while the subject of the study is theoretical and methodological guidelines for improving the competitiveness management of the motor transport enterprises. It is assumed that the implementation of the results of the study will improve the scientific level of managing the enterprises competitiveness, the level of occupying a decent position in the market.

\section{Review of the literature and theoretical foundations}

The central place in the economic systems management, including enterprises, competitiveness, etc., is taken by strategic management, it is proposed to use two approaches: market and resource in its implementation.

Nowadays, a market approach has become more widely used, the main ideologists of which were the Harvard Business School scientists and M. Porter, each of them presented their own versions of the approach to the enterprise strategy development. It is generally accepted that 1960 is the beginning of the company's research strategy, when three books of the management theory founders were published: "Strategy and Structure" by A. Chandler [1], "Business Policy" by K.R. Andrews [2], the fundamental work by I. Ansoff "Corporate Strategy" [3].

These fundamental results enable to form the current methodology for the overall enterprise strategy development. These results are outlined in many textbooks and teaching aids about strategic management. In accordance with them, the enterprise's strategy is enlarged in the following sequence: analysis of the external environment - establishing the presence of opportunities and threats for the enterprise in the environment - identifying its strengths and weaknesses; SWOT-analysis - the establishment of alternatives for the enterprises strategic development, the selection of the best ones.

The second variant of the market approach to the development of a competitive strategy for an enterprise was proposed by M. Porter - in the 1980s he promoted the idea of a "value chain". M. Porter found that the position of an enterprise - the results of operations and their sustainability- is determined by five competitive forces operating in the industry: competitors operating in the industry, potential competitors, suppliers, buyers, and substitute goods [4]. Profitability in the industry as a whole is determined by the action of the five forces listed above, since they affect prices, costs and the level of required investment. The efficiency of enterprises in the industry depends on the ability of the enterprise to resist the market power of suppliers and consumers, threats from potential competitors and substitutes, competition between competitors in the market.

Thus, with a market approach in the first case, the strategy of an enterprise is determined by adapting its potential to environmental factors, in the second case by adapting the potential of the enterprise to the conditions of the industry and competition. A common feature of the market approach is the direction of the strategy developing process from top to bottom - from the upper to the lower management level.

Since the mid-1990s, practical and theoretical conditions have arisen for the further transformation of the strategic management theory, changes in the content of an enterprise strategy and the approach to its formation, called the resource approach.

The theoretical basis for the development and use of the resource approach, the transformation of the strategic management theory, changes in the content of the strategy and the approach to its definition, were mainly the studies by Chamberlain and Rubenson (1930), Ed. Penrose (1959), J. Barney (1991), C. Wernerfelt (2006), G. Hamel and I. Prokhalada (1994).

Further development of the resource approach was K. Wernerfelt's organization theory [5], in which the author substantiated the feasibility of analyzing the company in terms of resources rather than products, and called it possibly a new paradigm in the theory of strategic management. Therefore, the starting point of the resource approach application is the 
establishment and evaluation of those resources characteristics that will allow the enterprise to increase its competitiveness and obtain a upper level of profitability.

G. Hamel and C. Prahalad made the most significant contribution to the development of the strategic management theory and the resource approach development, who proposed the theory of corporation key concepts, the methodology for developing an enterprise strategy based on its root competencies [6].

Taking into account the resource approach prerequisites: organizations within the same industry differ significantly from each other according to the possession and control of the resources available to them; resources are not mobile and therefore the resource heterogeneity of different enterprises within the same industry can persist for a long time; methods of the market approach and the characteristics of the study's object - the used resources homogeneity and the working conditions of enterprises are proposed to combine a market and resource approach to develop a strategy.

At the upper level, there is a potential positioning of the external environment enterprise requirements. At the level of individual strategic business units (SBU) - analysis by the method of M. Porter, the possibilities are determined on the basis of the resource approach provisions. Formation of a common competitiveness management strategy is a compromise of a common strategy project with SBU enterprise strategies.

\section{Results and discussion}

Enterprise competitiveness management is a specific function that is implemented by a certain composition of the management system. Its main components are: subsystem, elements, components, structure, and goals.

Currently, there is no unambiguous definition of the "control system" concept. The following definition of a management system is proposed: it is a set of subsystems, elements and interconnections between them, that ensure the functioning of the management process in the direction of an object (system, enterprise) achieving its goals.

Managed subsystem (control object) - a subsystem that is experiencing the control actions and executes management commands. By object of management, we mean an organized part of the environment - processes, phenomena, systems that give rise to a problem situation and solve it under the influence of management influence.

A management subsystem or a management entity is a person or a group of individuals who set themselves management tasks, detail them in the form of tasks, bring to the management object and control their implementation. It consists of three subsystems: structural and functional, self-developed, and informational and behavioral.

Structural functional subsystem is designed to implement the methods, principles and functions of management. It is represented as a control loop that combines all control functions in a single cycle.

Structural functional management subsystem (SFS) is a set of management bodies, departments and executors performing the functions assigned to them and solving the set tasks, as well as a set of methods by which management influence is implemented. Previously, it was decided to consider SFS as the actual management system. The structuralfunctional subsystem acts as the backbone of the control system.

At all levels of management, the SFS consists of three blocks of basic management functions: decisive $-\mathrm{D}$, conversion $-\mathrm{R}$, and information and control $-\mathrm{I}$. On the extended cycle, decision-making functions are performed in the decisive unit. In the conversion unit, the decisions made in the decision unit are implemented. In the information and control unit information is collected, the managing object control and regulation are done.

The final step in developing an enterprise management system is kinematics management. Two more subsystems should be distinguished in the structure of the control subsystem: information-behavioral and self-development. 
A managed system is a group of particular management objects that stand out from a common management object for various reasons. So, on the basis of the structural subdivisions of they are distinguished on such particular objects as - motor convoy 1 , motor convoy 2, etc.; by types of resources used - fixed assets, labor resources, etc.; according to the results of activity - the volume of work, the competitiveness of the enterprise, the competitiveness of services, etc.

In the managed subsystem, the management process is carried out - the sequential execution of management functions, allowing to coordinate a set of actions that allow the management object to achieve its goals. Based on the control cycle, separate control loops are formed - a closed set of control system elements. In the control loop, each element of the control system influences the next one, receiving influence from the previous one. Each control loop is aimed at solving problems of a specific control object - a structural unit of resource use or the achievement of certain results. The difference between the abstract cycle and the real control loop is in following: the management cycle reflects the logical sequence and interrelations of the main stages of control of any object. Control loops are always specific, as they are formed for individual objects. They are characterized by various goals, forms and methods of performing traditional management functions at all levels and stages of the management process. Therefore, each such circuit can be considered as a control system of the considered control object.

Thus, the management loop, which is formed using the management cycle as a model, focused on solving the problems of managing the enterprise and its services competitiveness, can be considered as a competitiveness management system. Depending on the object of management, there are systems for managing the competitiveness of an enterprise and the competitiveness of services.

The enterprise competitiveness management system is the outline of an enterprise management system aimed at establishing and achieving an planned level of competitiveness of the enterprise through the cyclical sequential execution of management functions (analysis, forecasting, planning, organization, motivation, regulation and control) by the enterprise's activities as a management object [7].

The system of competitiveness management of transport services is the outline of an enterprise management system aimed at achieving a business unit (type of transportation) of its services competitiveness established level through the cyclical sequential execution of the functions of managing the supply process and providing services.

The design and description of such systems begins with the establishment of management levels. Currently, there is no consensus among scientists regarding the number of enterprise management and their content levels, including competitiveness management. E.g., M.Kh. Meskon proposes to distinguish three levels of the management structure: top management, middle management and lower management [8].

Representatives of the second approach are scientists, authors of textbooks and technical aids on strategic management: F.R. David, D. Thompson, R. Lynch, I. Ansoff, Z.E. Shershencheva, B.M. Mizyuk, S.A. Panov, V.N. Parakhina. They offer a four-level model of the organizational structure of management: the upper level - the general strategy of the enterprise, the middle level - the business strategy, the level of functional strategies management, and the lower level.

Considering that the first approach reflects an objectively existing hierarchy, the following levels of management in a diversified enterprise are assumed: upper, middle and primary. So we should provide the implementation of the strategic management functions at the upper and middle level. At the middle level, business strategies should be developed. In the motor transport enterprise, the development of business strategies is necessary for each bus route, for each customer served. For the structure of a diversified enterprise, a model of the management system structure is proposed in Figure 1. 


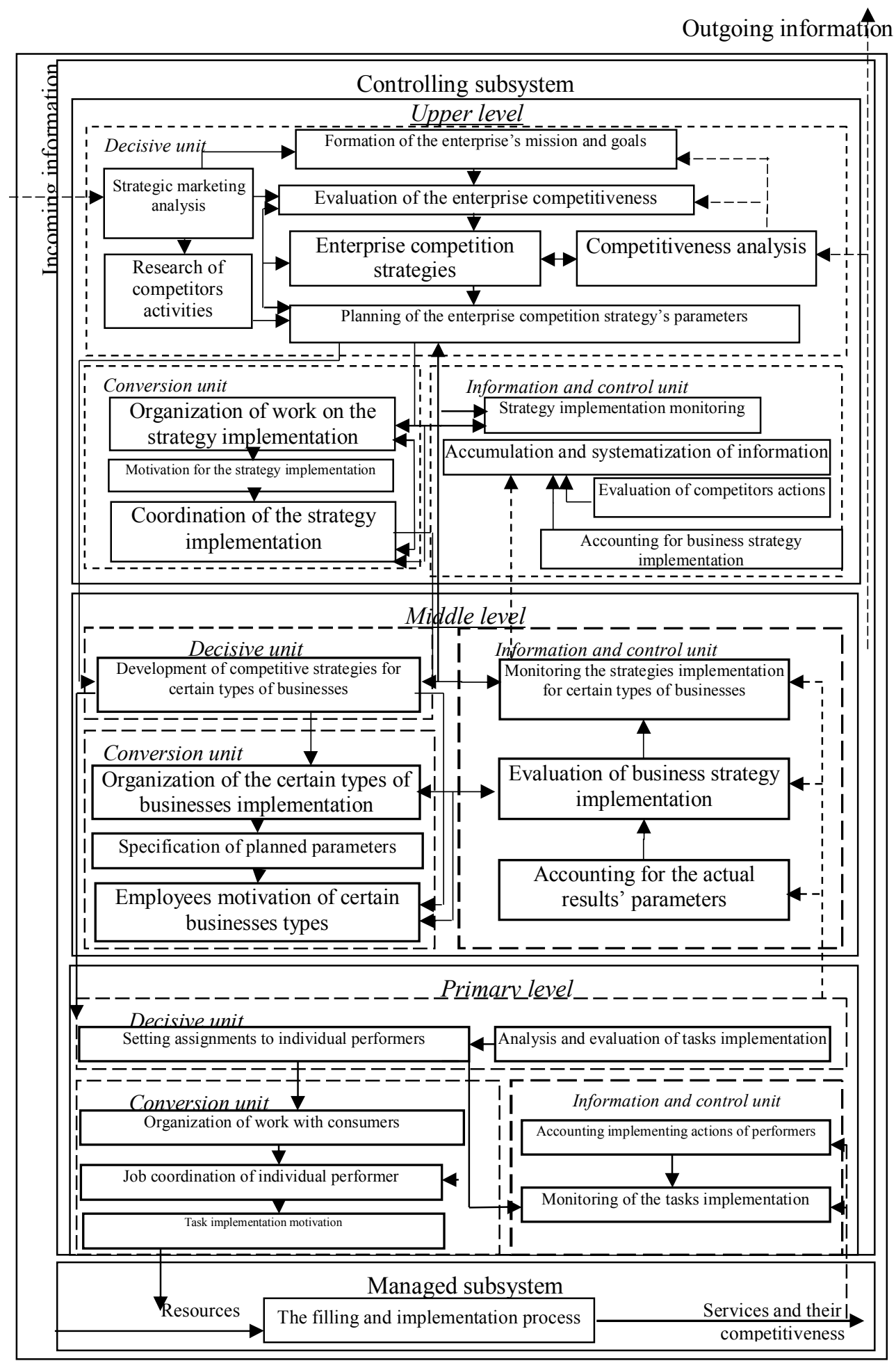

Fig. 1. The model of proposed structure of the enterprise competitiveness management system 
Experts in the field of strategic management in their works provide for the presence of functional strategies in the enterprise strategies composition. Their goal is to prepare solutions in the areas of finance, marketing, personnel, investment, etc. In our opinion, it is not expedient to single out a separate hierarchical level of management decision-making on the previously considered issues, because of the following reasons: solutions, prepared by functional service workers, are not always take into the account all the diversity, especially the external conditions of the control object operation; final decisions on them are made at each level by the first person; the amount of functional services management work at the first and second level is different.

The solution of this problem is seen in the use of a three-level organizational management structure and the creation of functional services at each management level, which are vertically subordinate to the upper level, and horizontally to the line manager.

Heads of functional units on the basis of proposals of all SBU within the limits of available resources form the functional strategy of the enterprise. The last one, coordinated with the head of the enterprise, is submitted for discussions with line managers. After discussion and final approval, the functional strategy, together with other documents, is approved as the enterprise development strategy is adopted for implementation and implementation [10].

\section{Conclusion}

The following results of the study were obtained: a model of strategic competitiveness management of the enterprise was further developed, which, unlike the existing one, is based on a combination of a market and resource approach in the enterprise strategy development; concepts such as "competitiveness management of the enterprise and its services", "management system" were clarified; the methodology for elaborating a competitiveness management system was further developed, the novelty of which is the generalization of existing developments in this area; the enterprise competitiveness management structure in terms of the redistribution of the activities of functional units management work between the upper and middle management levels using a matrix structure was improved.

\section{References}

1. A.D. Chandler, Strategy and Structure. Cambridge, MA: MIT Press, (1962).

2. K.R. Andrews, The Concept of Corporate Strategy. Homewood, Il: Irwin, (1980).

3. H.I. Ansoff, Corporate Strategy: An Analytical Approach to Business Policy for Growth and Expansion. McGraw Hill Book Co.: N.Y., (1965).

4. M. Porter, Competitive Strategy. New York: The Free Press, (1980).

5. B. Wernerfelt, Strategic Management Journal, 5(2), 171-180 (1984).

6. G. Hamel, C. Prahalad, Competing for the Future. Boston, Massachusetts: Harvard Business School Press, (1994).

7. V. Shynkarenko, N. Popova, Economycs of transport complex, 30, 5-14 (2017).

8. M. Meskon, M. Albert, F. Hedouri, Fundamentals of management. Moscow, Delo Publ., (1999).

9. I. Fedotova, V. Shynkarenko, O. Kryvoruchko, International Journal of Engineering \& Technology, 7 (4.3), 445-450 (2018). 